\title{
PENERAPAN ARSITEKTUR EKOLOGIS DAN SUSTAINABLE PADA RUANG DAUR ULANG DAN REKREASI SAMPAH DI DADAP
}

\author{
Leah Alifahni ${ }^{1)}$, Martin Halim ${ }^{2)}$ \\ 1) Program Studi S1 Arsitektur, Fakultas Teknik, Universitas Tarumanagara, leah.315160249@stu.untar.ac.id \\ 2) Program Studi S1 Arsitektur, Fakultas Teknik, Universitas Tarumanagara, martinhalim90@gmail.com
}

Masuk: 04-07-2021, revisi: 14-08-2021, diterima untuk diterbitkan: 23-10-2021

\begin{abstract}
Abstrak
Daur ulang adalah proses mengolah sampah menjadi bahan baru yang bisa digunakan kembali dan dimanfaatkan. Jenis sampah yang paling banyak dan sulit diuraikan salah satunya adalah plastik dan kaleng. Bangunan Daur Ulang dan Rekreasi sampah ini bertujuan untuk mengurangi sampah yang berada di Dadap kemudian akan didaur ulang (plastik dan kaleng) yang sudah dipilih, lalu dijadikan material bangunan yang akan dijual serta sebagai pengalaman baru dalam pembelajaran, yang dimana mengaplikasikan sampah tersebut dalam bentuk temporari exhibition pada rekreasi. Dan diharapkan bisa mensejahterakan kehidupan masyarakat dalam perekonomian. Strategi pengelolaan sampah itu sendiri terdiri atas 4 kegiatan utama yaitu, pemilahan, pengumpulan, pemprosesan, dan pendistribusian (hasil produksi) komponen utama dalam daur ulang serta hierarki 4R (reduce, reuse, recycle, and replace). Selain daur ulang dan rekreasi, program pendukung lainnya berupa edukasi dan RTH. Proyek ini menggunakan metode perancangan dengan menerapkan 5 prinsip arsitektur ekologis (pemanfaatan potensi iklim, penyediaan RTH, material lokal (penerapan3/4R), pengelolaan air, tanah, dan udara berkelanjutan dan ruang masyarakat).
\end{abstract}

Kata kunci : Daur Ulang Sampah; Edukasi, Jenis Sampah; Rekreasi; Ruang Publik; 3-4R

\begin{abstract}
Recycling is the process to turn waste into new materials that can be reused and utilized. The most numerous and difficult types of garbage to decipher one of them is plastic and cans. The building of the Waste Recycling and Recreation Center aims to reduce the waste that is in Dadap then will be recycled (plastic and cans) that have been selected, then used as building materials to be sold and as a new experience in learning, which applies the waste in the form of temporary exhibition like in recreation. And it is expected to prosper people's lives in the economy. The waste management strategy itself consists of 4 main activities, namely, sorting, collection, processing, and distribution (production results) of the main components in recycling as well as the $4 R$ hierarchy (reduce, reuse, recycle, and replace). In addition to recycling and recreation, other supporting programs include education and RTH. The project uses design methods by applying 5 principles of ecological architecture (utilization of climate potential, provision of RTH, local materials (application of 3/4R), water management. Land, and sustainable air and community space).
\end{abstract}

Keywords: Education; Public Space; Recreation; Types of Waste; Waste Recycling; 3-4R

\section{PENDAHULUAN}

Latar Belakang

Kabupaten Tangerang merupakan salah satu wilayah yang mengalami perkembangan penduduk yang sangat pesat. Dengan adanya hal tersebut, maka hal ini akan mempengaruhi kuantitas dan kualitas sampah yang dihasilkan (70\% sampah domestik dan $30 \%$ sampah non domestik). 
Dadap merupakan salah satu kelurahan yang berada di Kecamatan Kosambi, Kabupaten Tangerang, Banten, Indonesia, yang perlu dikelola. Karena menumpuknya sampah dalam jumlah besar di bantaran Sungai Dadap yang didapat dari faktor kurangnya kepedulian, pengetahuan warga dan minimnya bank sampah di tingkat wilayah (kurang lebih $60 \%$ belum memiliki bank sampah) sehingga menambah volume sampah yang dibuang pada lingkungan bantaran sungai.

Sampah-sampah yang berada di bantaran sungai maupun di bank sampah lebih banyak dihasilkan dari sampah rumah tangga. Berdasarkan jumlah per rumah, sampah rumah tangga bisa menghasilkan kurang lebih 1,71 kg/hari dan menghasilkan 44.1 ton dalam lingkup Kecamatan Kosambi. Jenis sampah pada rumah tangga yang paling banyak ditemukan di Dadap yaitu sampah plastik (yang sulit dihancurkan), dan sampah lainnya. Oleh karena itu, sangat diperlukannya kegiatan daur ulang atau tempat daur ulang yang bertujuan untuk memanfaatkan, dan mendaur ulang kembali sampah-sampah yang sulit dihancurkan menjadi barang yang bisa digunakan kembali, dijual, maupun dibuat menjadi material bangunan.

\section{Rumusan Masalah}

a. Apa saja dampak negatif dari sampah terhadap kesehatan manusia, lingkungan hidup dan lainnya?

b. Arsitektur yang bagaimanakah yang bisa mewadahi dan membantu mengurangi sampah?

c. Pendekatan seperti apa yang bisa menciptakan Arsitektur ekologi dalam menyelesaikan masalah Sampah ini?

\section{Tujuan}

Tujuan proyek ini adalah mewadahi aktivitas mendaur ulang sampah yang sulit dihancurkan (plastik dan kaleng) untuk dijadikan material bangunan yang akan dijual, mewadahi aktivitas rekreasi, edukasi dan ruang terbuka hijau untuk masyarakat. Selain itu, agar bisa menciptakan hubungan masyarakat yang selaras pada lingkungan alam dengan tidak merusaknya dan mensejahterakan perekonomian.

\section{PENDAHULUAN \\ Ekologi}

Pengertian Ekologi

Istilah Ekologi yang berasal dari kata Yunani oikos ("habitat") dan logos ("ilmu"), merupakan studi yang mempelajari hubungan antara organisme dengan lingkungannya dan yang lainnya. Dikutip dari Haeckel/tahun 1968, ekologi merupakan studi yang mempelajari baik hubungan timbal balik antar makhluk hidup maupun hubungan antara makhluk hidup dan lingkungannya. Komponen biotik yang terdiri dari makhluk hidup atau organisme dapat dikenal perwujudannya sebagai individu, populasi atau komunitas. Perwujudan tersebut masuk dalam kategori ruang lingkup ekologi yang dibagi menjadi beberapa bagian, yaitu :

- Individu : Individu adalah spesies atau jenis tertentu yang terdiri hanya satuan organisme. Misalnya : seorang manusia, seekor gajah, seekor burung, dan sebagainya

- Populasi : Populasi adalah suatu kelompok individu sejenis yang berada di suatu tempat dan waktu tertentu. Misalnya populasi manusia, populasi burung, populasi rumput, dan sebagainya.

- Komunitas : Komunitas adalah suatu kelompok yang terdiri dari mahluk hidup atas beberapa populasi dan saling berinteraksi satu sama lainnya pada suatu tempat dan waktu tertentu. Misalnya populasi rumput, populasi belalang, populasi burung, dan sebagainya 
- Ekosistem : Ekosistem hubungan timbal balik dan saling ketergantungan antara mahluk hidup dengan lingkungannya. Misalnya ekosistem hutan, air laut dan lainnya

- Biosfer : Biosfer adalah organisasi biologi yang paling utama, yang dimana di dalamnya terdapat semua kehidupan di bumi saling berinteraksi satu sama lain dan sebagainya

\section{Manfaat Ekologi}

Ada banyak manfaat ekologi yang bisa diberikan kepada manusia dan lingkungan hidupnya. Yaitu sebagai berikut :

- Mengenal keberagaman hayati

- Mengenal perilaku makhluk hidup

- Mengetahui peran mausia terhadap lingkungan

- Memecahkan masalah kesehatan

\section{Beyond Ecology}

Sistem yang saling terhubung dan berinteraksi dengan sebuah kondisi ekosistem dan sosial yang mengalami kondisi kecepatan dan percepatan. Pada kondisi tersebut, kecepatan menjadi jantung dunia keseharian dan ekosistem. Beberapa parameter beyond ecology dalam arsitektur :

- Sustainable Digital: melihat data-data ekosistem sebagai sebuah taktik dan strategi membangun kualitas spasial.

- Energy Emission : untuk meminimalisir efek $\mathrm{CO}^{2}$, menggunakan material dan konstruksi hemat energi, tidak berdampak untuk kehidupan.

- Context: merupakan peran penting yang menjadi central, dapat menjadi peluang untuk membaca, menginfestigasi, dan untuk memunculkan ide-ide baru dalam konsep beyond ecology.

\section{Ekologi Dalam Arsitektur}

Arsitektur ekologis merupakan pembangunan yang memperhatikan lingkungan sekitar, dimana memanfaatkan potensi alam semaksimal mungkin dengan memperhatikan bentuk bangunan, konstruksinya dan lingkungan sekitarnya dengan menggunakan pola perencanaan. Yaitu :

- Dinding dan atap gedung : melindungi dari panas, hujan.

- Intensitas energi baik yang terkandung dalam bahan bangunan harus semaksimal mungkin

- Memperhatikan orientasi agar mendapatkan cahaya dan lainnya secara efektif

\section{Arsitektur Yang Sadar Lingkungan}

- Holistik : Eko-arsitektur bersifat luas yang mengandung semua bidang ( biologis, alternatif, matahari, bionik dll). Untuk keselarasan antara manusia dan lingkungan alamnya.

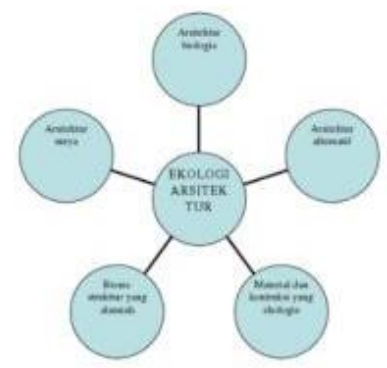

Gambar 1. Bagan Holistik

Sumber: Ayodhia Mahardika Blog ,2013

- Hemat energi : perlunya penghematan energi, agar tidak terjadi pemanasan global 
- Material Ramah Lingkungan : penggunaan bahan bangunan yang tidak berbahaya, menggunakan bahan baku, air, dan energi semaksimal mungkin, dan bahan yang digunakan harus kuat dan tahan lama

\section{Sampah}

\section{Pengertian Sampah}

Dikutip dari Soemirat/tahun 1994, sampah adalah barang padat yang dihasilkan dari kegiatan manusia yang tidak lagi dikehendaki. Sampah biasanya bersumber dari rumah tangga, industri, fasilitas umum maupun fasilitas sosial lainnya.

\section{Jenis-Jenis Sampah}

Jenis sampah dibagi menjadi 2. Pertama yaitu Sampah Organik, sampah yang mudah dihancurkan dan bersifat mikroba seperti sayur, buah dll. Kedua, Sampah NonOrganik yaitu sampah yang sulit dihancurkan, contoh : plastik, kaca, kayu dll.

Selain terbagi menjadi organik dan nonorganik, sampah juga dibagi dalam 2 kategori, yaitu : padat ( pecahan gelas, kaleng bekas dII) dan cair ( sampah cair dapur, cair toilet dll )
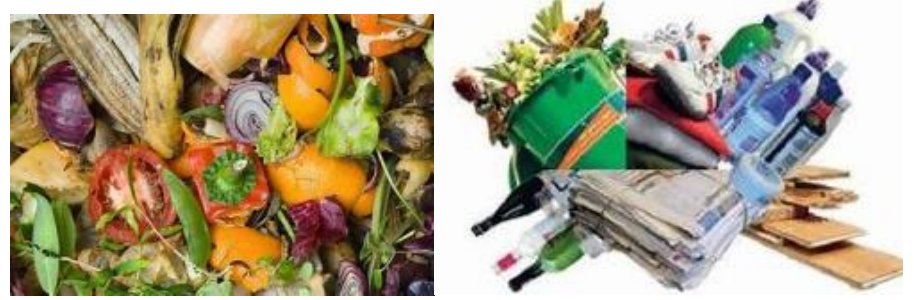

Gambar 2. Sampah Organik dan Nonorganik Sumber: Google , 2021

\section{Penanganan Dengan $3 R$}

Penanganan sampah dapat dilakukan dengan cara 3R yaitu :

- Reuse (Menggunakan Kembali) : menggunakan kembali baik secara fungsi atau bukan.

- Reduce (Mengurangi) : mengurangi dengan berbagai cara agar tidak menimbulkan tumpukan sampah

- Recycle (Daur Ulang) : Mendaur ulang kembali untuk dijadikan sesuatu yang baru dan bisa digunakan

Alat Mesin

- Mesin Pencacah Organik : berfungsi untuk mencacah berbagai jenis sampah organik dan nonorganik

- Mesin Shredder : dikhususkan untuk nonorganik karena memiliki pisau yang berbentuk bulat dan hexagonal. Namun, bisa digunakan untuk mencacah sampah organik

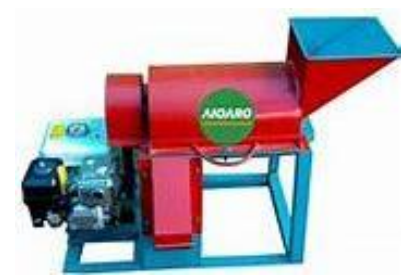

Gambar 3. Mesin Pencacah Organik Sumber: Google ,2021

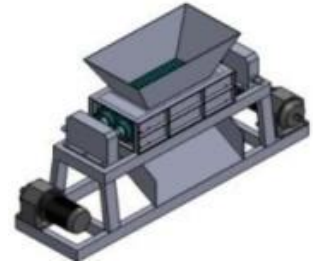

Gambar 4. Mesin Shredder

Sumber: Google, 2021 
Jenis-Jenis Tempat Sampah

Berbagai negara, sudah melakukan dan membuat perbedaan tempat sampah berdasarkan warnanya. Tempat sampah tersebut berfungsi untuk memisahkan jenis sampah organik, non organik, B3, kertas dan residu, yaitu : hijau (sisa makanan, ranting pohon yang dapat dihancurkan), kuning ( plastik bekas, gelas dII ), merah ( untuk B3, berbahaya, beracun ), biru ( khusus kertas), dan abu-abu ( sampah selain 4 jenis yang sudah disebutkan ).

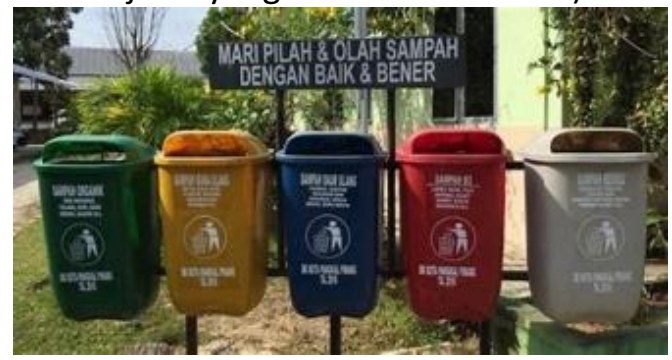

Gambar 5. Tempat Sampah

Sumber: Google, 2021

\section{Sistem Pengangkutan Sampah}

Sistem pengangkutan sampah biasanya dari sumber sampah terlebih dahulu kemudian ke TPS dan selanjutnya dibawa ke TPA menggunakan truk.

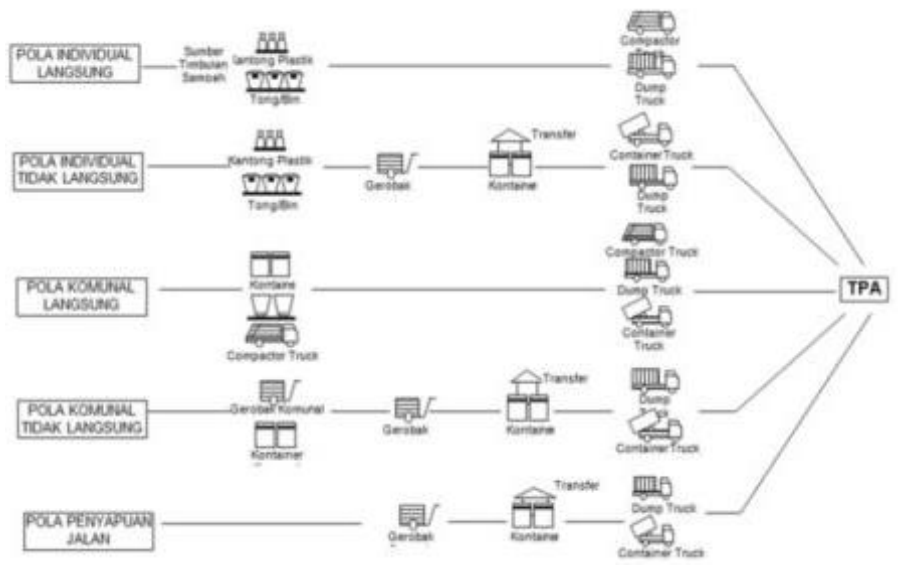

Gambar 6. Sistem Pengangkutan Sampah Sumber: SNI 19-2454-2002

Manfaat Sampah

- Sebagai pupuk organik untuk tanaman

- Sebagai sumber humus

- Di daur ulang menjadi berbagai jenis produk yang bermanfaat

- Dapat dijadikan bahan bakar alternatif

\section{Dampak Negatif Sampah}

- Penyakit diare, kolera, tifus dll pada manusia

- Penyakit jamur dapat juga menyebar (misalnya jamur kulit) pada manusia

- Rusaknya lingkungan alam sekitar (banjir, longsor dIl)

- Hilangnya dan berkurangnya ekosistem yang membutuhkannya 


\section{METODE}

\section{Prinsip Arsitektur Ekologis}

Pendekatan metode dalam mendesain proyek ini adalah bagaimana menciptakan suatu unsur ekologis pada Ruang Daur Ulang dan Rekreasi sampah, agar bisa menyatukan alam dengan aktivitas masyarakatnya. Pendekatan metode ini mengambil beberapa metode prinsip teori ekologis dari Frick (2007), Widigdo (2008), Metallinaou (2006), dan Yeang (2002), yaitu :

- Pemanfaatan Potensi Iklim (Yeang, 2002) - ( pendekatan Bioclimatic - Passive and Low Energy System) : orientasi yang mengarah ke Utara dan Selatan untuk memaksimalkan bukaan, permainan ketinggian bangunan untuk menciptakan self Shading, dan adanya bidang transparan

- Penyediaan RTH : penggunaan unsur alam berupa penghijauan, air, dan tanaman gantung

- Material lokal (penerapan3/4R) : Adanya bagian yang menggunakan material ramah lingkungan ( lokal) dengan memperhatikan emisi karbon rendah ( batu bata : emisi CO2 : 0,026, kaca : emisi CO2 : 0,22 dan lainnya), tidak beracun dan yang bisa di daur ulang kembali.

- Pengelolaan air. Tanah, dan udara berkelanjutan : penggunaan paving block (dari hasil daur ulang sampah ) untuk pengerasan jalan serta penyerapan air ke tanah

- Penyediaan Ruang Masyarakat : ruang publik untuk konektivitas antara bangunan dengan masyarakat

\section{HASIL DAN DISKUSI}

\section{Lokasi Tapak}

Lokasi proyek ini dipilih karena berada di jalan utama yaitu Jalan Raya Perancis, Kelurahan Dadap, Kecamatan Kosambi, Kabupaten Tangerang dan memiliki jalan kecil yaitu Jalan Raya Dadap. Selain itu, lokasi ini juga cukup strategis untuk pencapaian dari fasilitas umum lainnya dan dekat dari sumber sampah. Menurut RTRW pada Kab. Tangerang, lokasi yang terpilih merupakan zona campuran. Kondisi eksiting tapak adalah ruko-ruko.
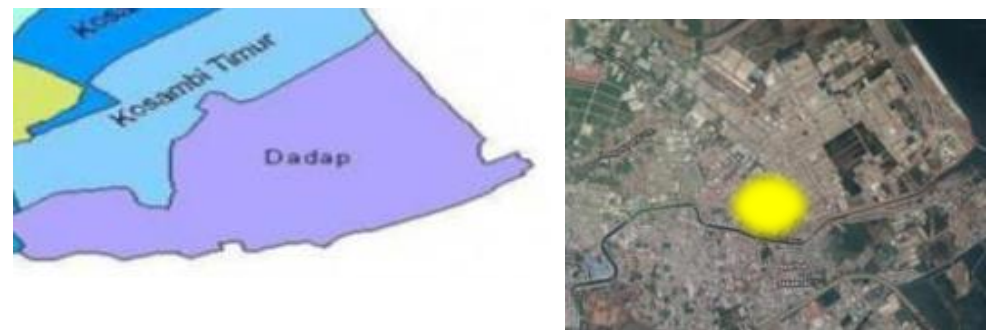

b. Sentra industri kecil dan menengah

Sentra industri kecil den menengah, meliputi : Kecamatan Tigaraksa, Kecamatan Pakuhaji, Kecamatan Sepatan, Kecamatan Balaraja, Kecamatan Jayanti, Kecamatan Pasar Kemis, Kecamatan Legok, Kecamatan Curug, Kecamatan Cikupa, Kecamatan Kosambi, Kecamatan Sepatan Timur, Kecamatan Jambe, Kecamatan Panongan, Kecamatan Pagedangan, Kecamatan Kelapa Dua, Kecamatan Teluknaga, Kecamatan Sindang Jaya, Kecamatan Sukadiri.

Gambar 7. Lokasi Tapak, dan Data Tapak Sumber: Google 2021, BPS Kab. Tangerang, 2020-2021 

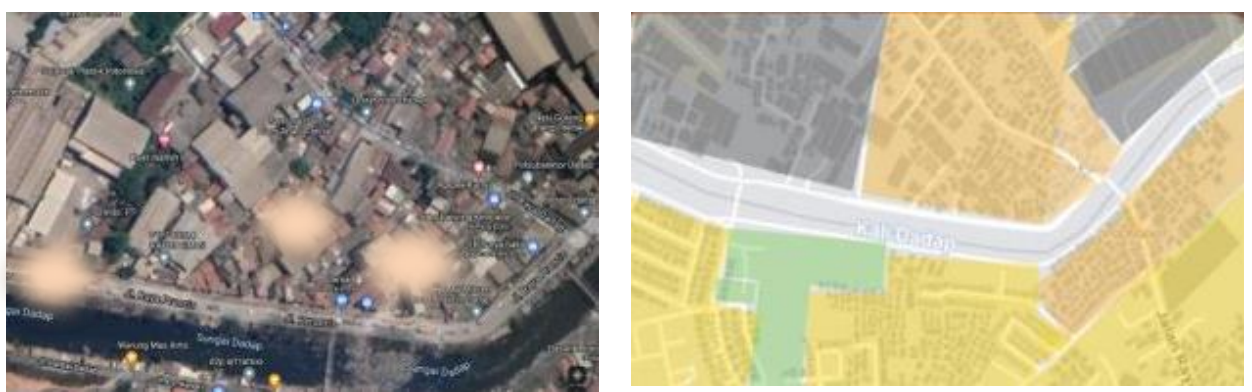

Gambar 8. Titik Sumber Sampah dan Zonasi Sumber: Google 2021, BPS Kab. Tangerang, 2020-2021

Data Penduduk

Data penduduk :

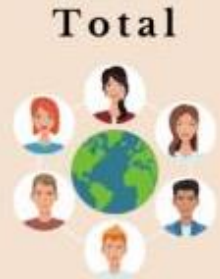

$38.152 / \mathrm{Jiwa}$

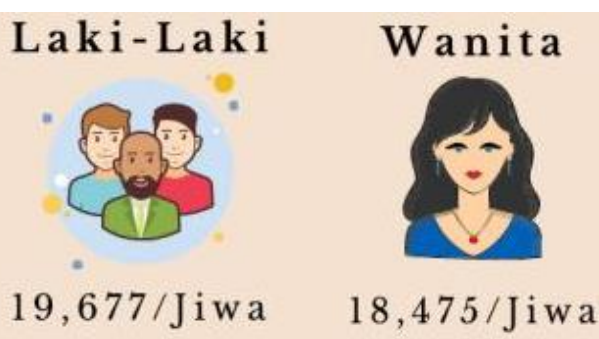

Gambar 9. Jumlah Penduduk Sumber: RTRW Kab. Tangerang (2011-2031)

\section{Data Ekonomi dan Sosial}

Jenis ekonomi dan sosial yang ada di Dadap yaitu pekerjaan dan pendidikan dengan presentase:

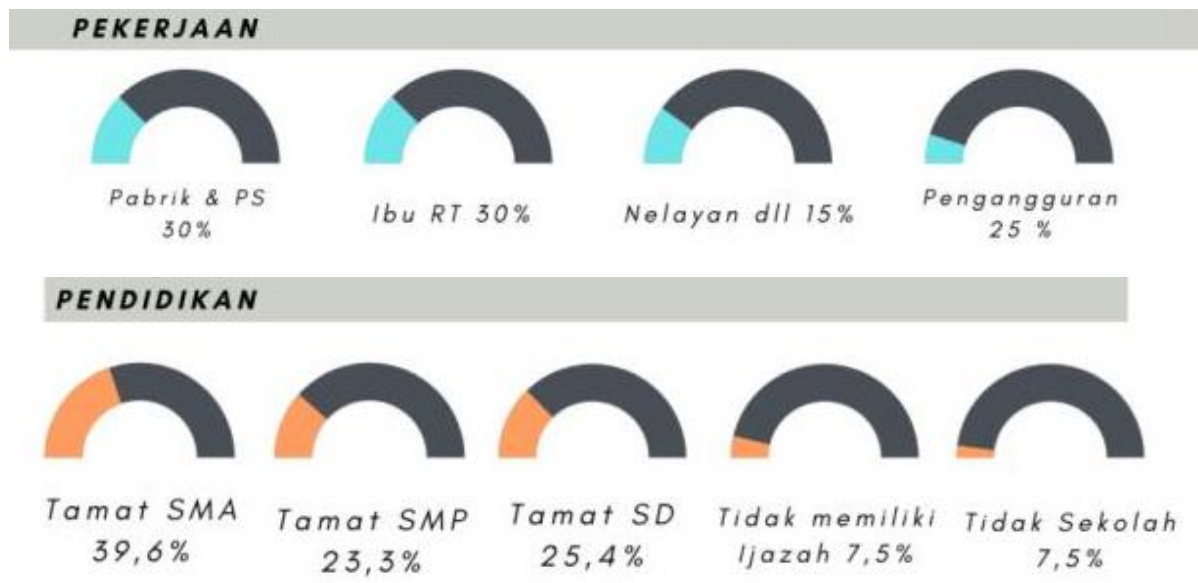

Gambar 10. Presntase Ekonomi dan Sosial Sumber: RTRW Kab. Tangerang (2011-2031) 


\section{Data Tapak}

Lokasi Tapak : Jl. Raya Prancis No. 47, Dadap, Kec. Kosambi, Kab. Tangerang

Kelurahan : Dadap

Kecamatan : Kosambi

Luas Tapak $: 5.400 \mathrm{~m}^{2}$

KDB $: 60 \%$

KLB $\quad: 1,2$

$\mathrm{KB} \quad: 2$

$\mathrm{KDH} \quad: 10 \%$

Peruntukan : Campuran (C.1)

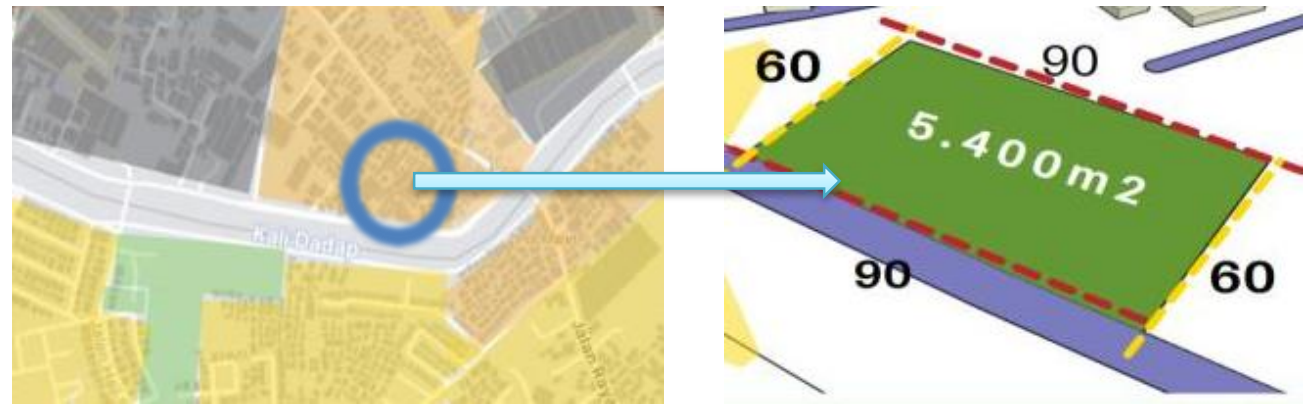

Gambar 11. Lokasi Tapak, dan Ukuran Tapak

Sumber: Pribadi dan Google Maps, 2021

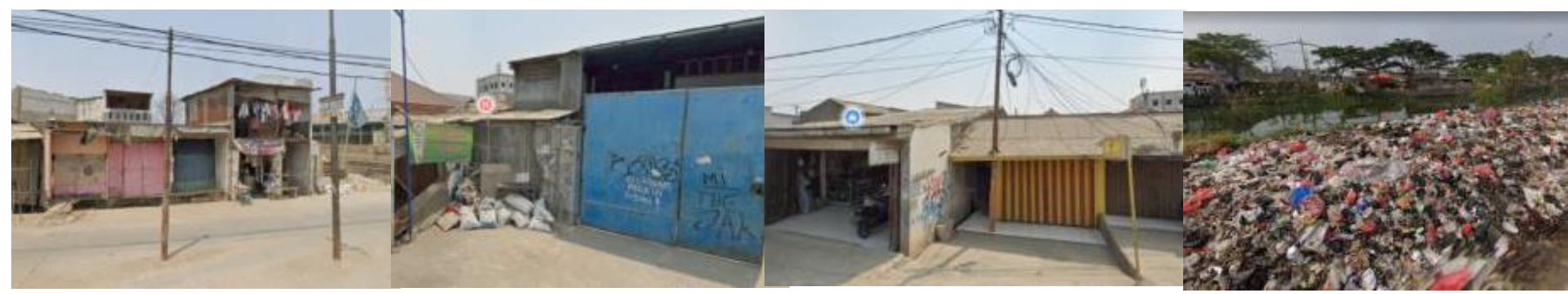

Gambar 12. Lingkungan Sekitar dan Sumber Sampah Sumber: Dadap,Google Maps, 2021

\section{Konsep Perancangan}

Bangunan fasilitas ini dirancang untuk mendaur ulang sampah plastik dan kaleng (sampah utama yang dipilih) menjadi material bangunan yang akan dijual serta diaplikasikan dalam temporari bangunan atau semacamnya pada rekreasi. Konsep pendekatan desain yang diterapkan yaitu dari konsep sustainable. 


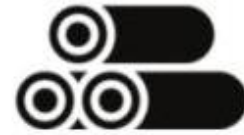

Material yang

ramah

lingkungan
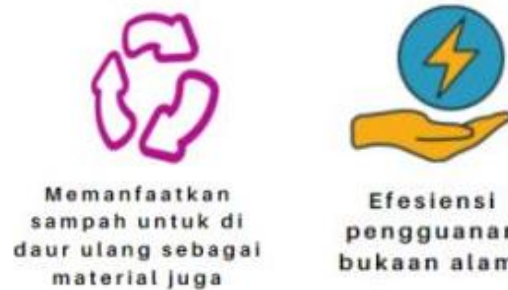

Efesiensi pengguanan bukaan alami

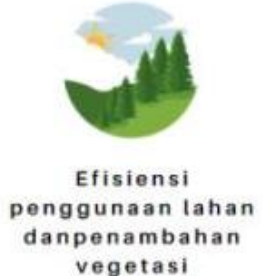

vegetasi

Gambar 13. 4 Konsep Sustainable

Sumber: Pribadi 2021

Selain itu, desain ini juga dirancang dengan banyaknya ruang-ruang yang terbuka agar mendapatkan pencahayaan dan udara alami serta adanya RTH untuk komunikasi ruang luar dan dalam dapat terjalin dengan baik.

\section{Program}

Dengan data yang didapat dari volume sampah $1,71 \mathrm{~kg} /$ hari nya yang dihasilkan dari rumah tangga serta di bantaran Sungai Dadap, maka program utama yang akan dirancang adalah Ruang Daur Ulang Sampah dengan program pendukung yaitu Rekreasi,Edukasi dan RTH.

- Ruang Daur Ulang : tidak hanya sebagai daur ulang tetapi untuk rekreasi pengalaman dalam belajar mengenai sampah, yaitu berkonsep memperlihatkan proses daur ulang sampah secara langsung yang tidak ramah lingkungan menjadi bahan material bangunan yang akan dijual dan kemudian diaplikasikan juga dalam bangunan temporari sebagai rekreasi di program ini.

- Rekreasi : aplikasi dari daur ulang sampah untuk rekreasi pengunjung agar bisa merasakan pengalaman baru terhadap sampah yang sudah di daur ulang (exhibition atau semacamnya)

- Edukasi Workshop : Sebagai tempat untuk mendapatkan ilmu dari masalah sampah yang kemudian akan langsung dipraktekan dalam membuat suatu kerajinan tangan dari sampah.

- $\quad \mathrm{RTH}$ : untuk penunjang pengunjung yang datang agar bisa menikmati ruang terbuka alam

\section{Luasan Program Ruang}

Daur Ulang

\begin{tabular}{|c|c|c|c|c|c|c|c|}
\hline PELAKU & AKTIVITAS & SIFAT AKTIVITAS & KEBUTUHAN RUANG & 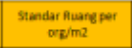 & $\begin{array}{l}\text { Kaph arang } \\
\text { per ruangs }\end{array}$ & Jumlah Ruang & Sumber \\
\hline \multirow{22}{*}{ Karyawan R. Daur Ulang } & Mengecek Keluar Masuk Pegawai \& Pengunjung & Publik & Lobby & 56 & 20 & 1 & $P A$ \\
\hline & Menjaga keamanan bangunan & Publik & Pos Jaga & 8 & 2 & 1 & $O A$ \\
\hline & Menerima Sampah dalam bak pengumpulan & Privat & Loading Dock Drop Off Sampah & 48 & 5 & 1 & Falko Weber \\
\hline & Mengawasi Pemilahan Sampah & Privat & Kantor Pengawasan & 48 & 3 & $4 \mathrm{~m} /$ Unit & $\mathrm{MH}$ \\
\hline & Memilah sampah sesuai jenis & Privat & R. Pemilahan & 48 & 15 & 3 jenis ( $1 \mathrm{~m} /$ jenis) & DA \\
\hline & Menyimpan barang dan semacamnya & privat & Gudang Alat Berat & 60 & 2 & 4/Unit & DA \\
\hline & Memasukan Sampah Ke Alat Pencacah & Privat & Area Pencacahan & 120 & 6 & 1 & \multirow{3}{*}{ A } \\
\hline & Memasukkan cacahan sampah ke bak pencampuran & Privat & R. Pencampuran & 120 & 6 & 1 & \\
\hline & Pemindahan Hasil Campuran Sampah ke cetakan & Privat & R. Pencetakan & 120 & 6 & 1 & \\
\hline & Pemindahan Hasil Produksi dan Ruang Jual & Privat & R. Produksi & 120 & 15 & 4 jenis & DA \\
\hline & Aktivitas Jual-Beli Hasil Produk & Semi Publik & R. Marketing Produksi & 45 & 2 & 1 & HAB \\
\hline & Mencudi Sampah yang Kotor & Privat & R. Pencucian & 36 & 4 & 1 & \multirow[b]{2}{*}{ A } \\
\hline & Mengeringkan Sampah Setelah di Cuci & Privat & R. Pengeringan & 36 & 4 & 3 & \\
\hline & Melakukan uji coba hasil produksi sampah & Privat & R. Laboratorium Penelitian & 48 & 10 & 1 & \multirow{2}{*}{ NAD } \\
\hline & Area alat-alat penelitian & Privat & R. Peralatan & 30 & 3 & 1 & \\
\hline & Membuang sisaan daur ulang & Semi Publik & Area Pembuangan Sisaan & 48 & 2 & 1 & DA \\
\hline & Mengawasi Pemilahan Sampah & Privat & Area Pengawasan & 30 & 1 & 1 & MH \\
\hline & Drop Off Sampah di parkiran & Privat & Parkir Drop Sampah & 48 & 3 & 1 & Falko Weber \\
\hline & Aktivitas Pegawai & Privat & R. Pegawai & 30 & 4 & 1 & MH \\
\hline & Berganti Pakaian & Semi Privat & Area Loker Pegawai & 24 & 25 & 30 & \multirow{3}{*}{ DA } \\
\hline & \multirow[b]{2}{*}{ Melakukan bersih-bersih } & \multirow[b]{2}{*}{ Semi Publik } & \begin{tabular}{|c|} 
Toilet \\
\end{tabular} & & & & \\
\hline & & & \begin{tabular}{|l|}
4 WC +1 Wastafel Pria $20 \%$ Sirkulasi \\
4 WC +1 Wastafel Prp $20 \%$ Sirkulasi
\end{tabular} & $2,5 /$ Unit (48m2) & 5 & 2 & \\
\hline \multicolumn{4}{|c|}{ Total Luas Kebutuhan Besaran Ruang } & \multicolumn{4}{|c|}{$1.171 \mathrm{mz}$} \\
\hline \multicolumn{4}{|c|}{ Total Luas Kebutuhan Besaran Ruang + Sirkulasi $30 \%(351 \mathrm{~m} 2)$} & \multicolumn{4}{|c|}{$1.522 \mathrm{mz}$} \\
\hline
\end{tabular}




\section{Rekreasi dan Edukasi}

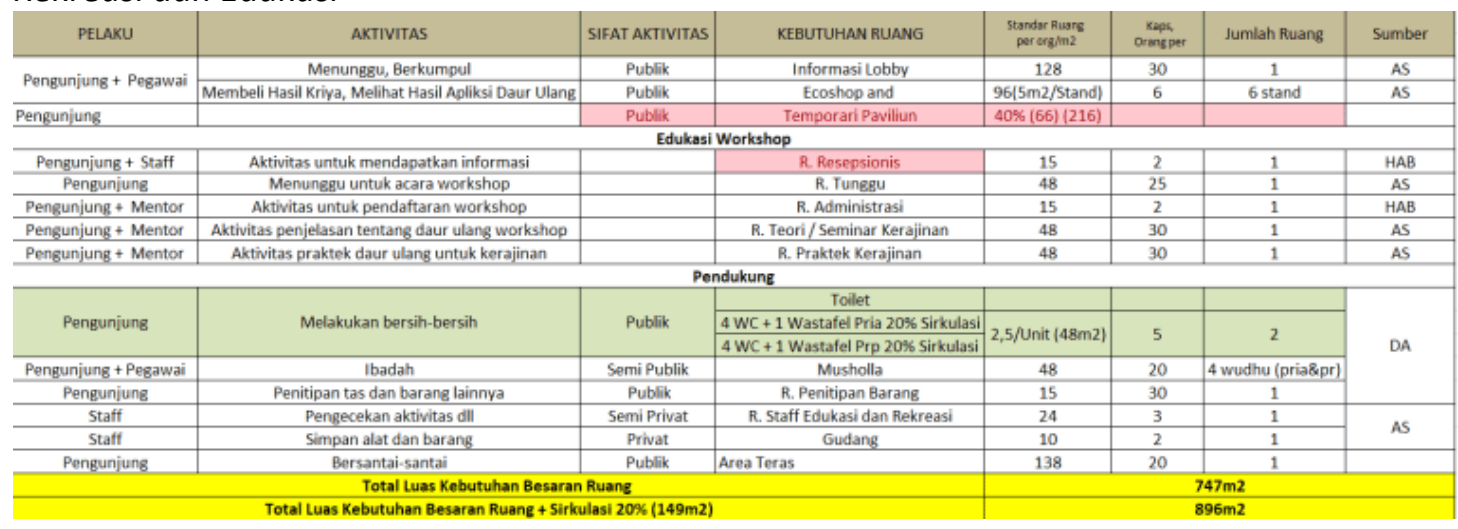

\section{R. Pengelola}

\begin{tabular}{|c|c|c|c|c|c|c|c|}
\hline PELAKU & AKTIVITAS & SIFAT AKTIVITAS & KEBUTUHAN RUANG & $\begin{array}{l}\text { Standar Ruang } \\
\text { per org/m2 }\end{array}$ & $\begin{array}{l}\text { Kaps, Orang } \\
\text { per ruang }\end{array}$ & Jumlah Ruang & Sumber \\
\hline \multirow{15}{*}{ Staff Pengelola } & Meminta / menanyakan infromasi & Publik & R. Infromasi & 40 & 2 & 1 & HAB \\
\hline & Mengawasi serta mengelola tiap program & Privat & R. Manajemen Pengelola & 32 & 2 & 1 & HAB \\
\hline & Mengawasi, mengontrol, dan memberikan & \multirow{2}{*}{ Privat } & R. Staff Pengoprasian \& & \multirow{2}{*}{48} & \multirow{2}{*}{15} & \multirow{2}{*}{1} & \multirow{2}{*}{ MH } \\
\hline & informasi untuk area daur ulang sampah & & pengolahan sampah & & & & \\
\hline & \multirow{2}{*}{ Melakakukan penjagaan \& pemeliharaan } & \multirow{2}{*}{ Privat } & Ruang staff pengawasan & \multirow[t]{2}{*}{48} & 8 & 1 & MH \\
\hline & & & $\begin{array}{l}\text { \& Pemeliharaan } \\
\text { R. Kepala Bidang Penjualan }\end{array}$ & & 1 & 1 & DA \\
\hline & Aktvitas memgontrol area rekreasi & Privat & R. Staff Bidang Rekreasi & 15 & 5 & 1 & $\mathrm{MH}$ \\
\hline & Penyimpanan berkas-berkas penting & Privat & Ruang arsip & 24 & 1 & 1 Unit = 4 & $\mathrm{MH}$ \\
\hline & Pertemuan untuk evaluasi & SemiPublik & Ruang rapat & 48 & 20 & 1 & DA \\
\hline & Isitirahat ( ISOMA) & Semi Publik & Pantry & 24 & 3 & 1 & A \\
\hline & Ibadah & Semi Publik & Musholla + area wudhu & $24+6(30)$ & 6 & 3 wudhu (pria\&pr) & \\
\hline & Penyimpanan alat kebersihan & Privat & Janitor & 2 & 1 & 1 & \\
\hline & \multirow{3}{*}{ Melakukan bersih-bersih } & \multirow{3}{*}{ Publik } & Toilet & \multirow{3}{*}{$2,5 /$ Unit $(36 \mathrm{~m} 2)$} & \multirow{3}{*}{5} & \multirow{3}{*}{2} & DA \\
\hline & & & 4 WC +1 Wastafel Pria $20 \%$ Sirkulasi & & & & \\
\hline & & & 4 WC +1 Wastafel Prp $20 \%$ Sirkulasi & & & & \\
\hline \multicolumn{4}{|c|}{ Total Luas Kebutuhan Besaran Ruang } & \multicolumn{4}{|c|}{$379 \mathrm{~m} 2$} \\
\hline \multicolumn{4}{|c|}{ Total Luas Kebutuhan Ruang + Sirkulasi $20 \%(76 \mathrm{~m} 2)$} & \multicolumn{4}{|c|}{$455 \mathrm{~m} 2^{2}$} \\
\hline
\end{tabular}

\section{Sevice}

\begin{tabular}{|c|c|c|c|c|c|c|c|}
\hline PELAKU & AKTIVITAS & SIFAT AKTIVITAS & KEBUTUHAN RUANG & $\begin{array}{l}\text { Standar Ruang } \\
\text { per org/m2 }\end{array}$ & $\begin{array}{c}\text { Kaps, Orang } \\
\text { per ruang }\end{array}$ & Jumlah Ruang & Sumber \\
\hline \multirow{10}{*}{ Karyawan Service } & & & R. MEKANIKAL & & & & \\
\hline & Mengecek dan perbaiki Pompa & Privat & R. Pompa & 16 & 2 & 1/Unit & AS \\
\hline & & & R. ELEKTRIKAL & & & & \\
\hline & Melakukam Pengecekan & Privat & R. Trafo dan Panel (2) & 18/ruang (36) & 2 & \multirow{3}{*}{$1 /$ Unit } & \multirow{3}{*}{ AS } \\
\hline & Mengecek dan perbaiki genset & Privat & R. Genset & 36 & 3 & & \\
\hline & Melakukam Pengecekan & Privat & Panel Cabang & 30 & 1 & & \\
\hline & \multicolumn{7}{|c|}{ SERVICE PENDUKUNG } \\
\hline & Ruang Penyimpanan & privat & Gudang & 24 & 5 & 1/Unit & AS \\
\hline & Aktivitas pegawai bengkel, istirahat dll & privat & Ruang Bengkel & 96 & 3 & 1/Unit & $\mathrm{MH}$ \\
\hline & Mengawasi Kegiatan Tiap Ruang & Privat & R. Pegawai & 24 & 5 & 4/Unit & AS \\
\hline \multirow{2}{*}{\multicolumn{4}{|c|}{ Total Luas Kebutuhan Besaran Ruang }} & \multicolumn{4}{|c|}{$262 \mathrm{~m} 2$} \\
\hline & \multicolumn{3}{|c|}{ Total Luas Kebutuhan Besaran Ruang + Sirkulasi $30 \%(79 \mathrm{~m} 2)$} & \multicolumn{4}{|c|}{$340 \mathrm{~m}^{2}$} \\
\hline
\end{tabular}


Parkir

\begin{tabular}{|c|c|c|c|c|c|c|c|}
\hline PELAKU & AKTIVITAS & SIFAT AKTIVITAS & KEBUTUHAN RUANG & $\begin{array}{l}\text { Standar Ruang } \\
\text { per org } / \mathrm{m2}\end{array}$ & $\begin{array}{l}\text { Kaps, Orang } \\
\text { per ruang }\end{array}$ & Jumlah Ruang & Sumber \\
\hline \multirow{2}{*}{ Staff Pengelola } & \multirow{2}{*}{ Parkir kendaraan pengelola } & \multirow{2}{*}{ Semi Publik } & \multirow{2}{*}{ Parkir Pengelola } & 75 & $15 \mathrm{~m} 2 / \mathrm{mobil}$ & 5 & \multirow{2}{*}{ DA } \\
\hline & & & & 60 & $2 \mathrm{~m} 2 /$ motor & 30 & \\
\hline \multirow{3}{*}{ Pengunjung } & \multirow{3}{*}{ Parkir kendaraan pengunjung } & \multirow{3}{*}{ Publik } & \multirow{3}{*}{ Parkir Pengunjung } & 90 & $15 \mathrm{~m} 2 / \mathrm{mobil}$ & 6 & \multirow{3}{*}{ A } \\
\hline & & & & 60 & $2 \mathrm{~m} 2 /$ motor & 30 & \\
\hline & & & & 20 & $2 \mathrm{~m} 2 /$ Sepedah & 10 & \\
\hline \multicolumn{4}{|c|}{ Total Luas Kebutuhan Besaran Ruang } & \multicolumn{4}{|c|}{$305 \mathrm{~m} 2$} \\
\hline \multicolumn{4}{|c|}{ Total Luas Kebutuhan Ruang + Sirkulasi 100\% (305m2) } & \multicolumn{4}{|c|}{$610 \mathrm{~m} 2$} \\
\hline
\end{tabular}

Gambar 14. Luasan Program Ruang

Sumber: Pribadi, 2021

\section{Konsep dan Transformasi Gubahan Massa}

Gubahan massa diproses dengan metode yang digunakan yaitu prinsip Arsitektur Ekologis yang merespon iklim, penerapan 3R / 4R dan sebagainya. Berikut gambar-gambar yang dijadikan sebagai representasi dari masing-masing prosesnya.

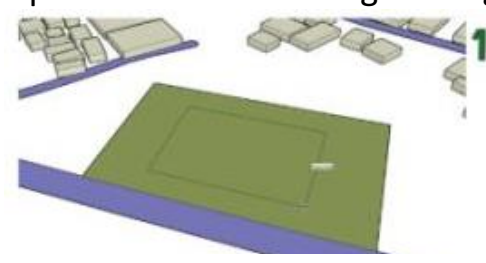

Memilih bentuk persegi yang cenderung memiliki potensi dalam keleluasaan ruang $\left(5.400 \mathrm{~m}^{2}\right)$

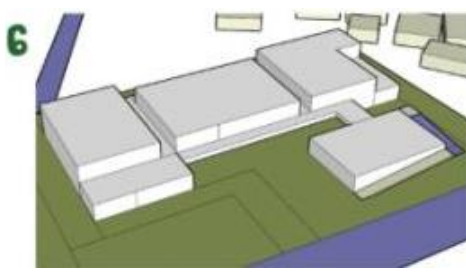

Final. Area tengah untuk RTH penghijauan dan parkir berada disisi

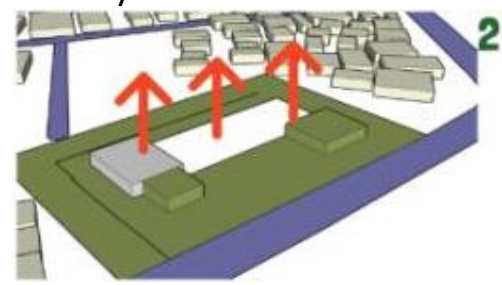

Sebagian bentuk dinaikkan menjadi 2 It menyesuaikan KB lingkungan

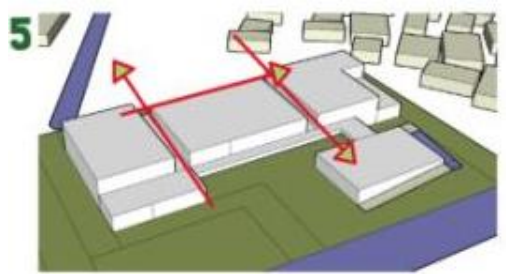

Adanya penyediaan sirkulasi aktifitas publik pada area tengah dan belakang bangunan

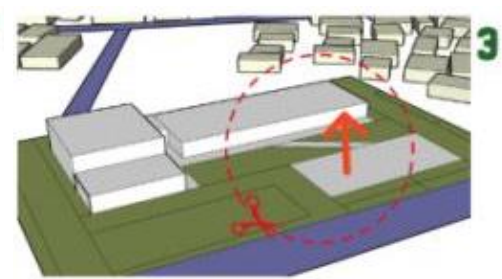

Adanya penambahan massa untuk area publik yang mengarah ke selatan dengan jarak +- $5 \mathrm{~m}$

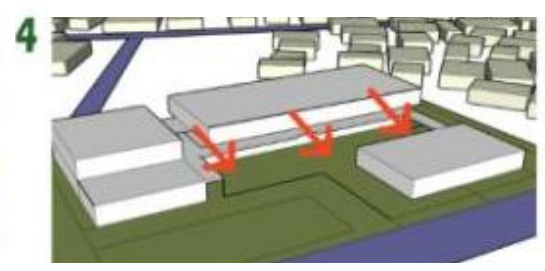

Penambahan bentuk untuk sirkulasi publik dengan persegi agar mendapatkan udara dan cahaya secara efektif, serta pandangan keseluruh massa luas

Gambar 15. Transformasi Gubahan Massa

Sumber: Pribadi ,2021

\section{Hasil Desain Rancangan Eksterior}

Hasil rancangan bangunan ini menerapkan pendekatan 5 prinsip Arsitektur Ekologis, yaitu :

- Pemanfaatan Potensi Iklim (Yeang, 2002) - ( pendekatan Bioclimatic - Passive and Low Energy Systtem) : 
Orientasi bangunan mengarah ke selatan dan utara. Sehingga memiliki banyak bukaan alami untuk pencahayaan dan pengudaraan

- Pengelolaan air. Tanah, dan udara berkelanjutan :

Penggunaan paving block pada in dan out pejalan kaki untuk penutup resapan air hujan ke tanah

Sumber: Pribadi, 2021

- Penyediaan RTH :

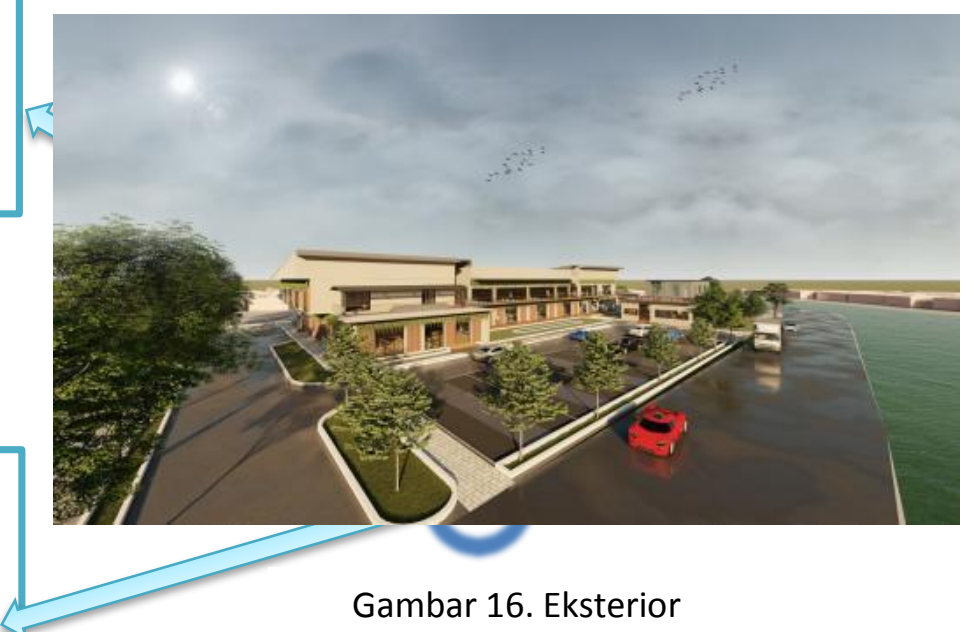

\section{Penggunaan vertical garden, taman, dan ruang terbuka hijau lainnya}

$\bullet$

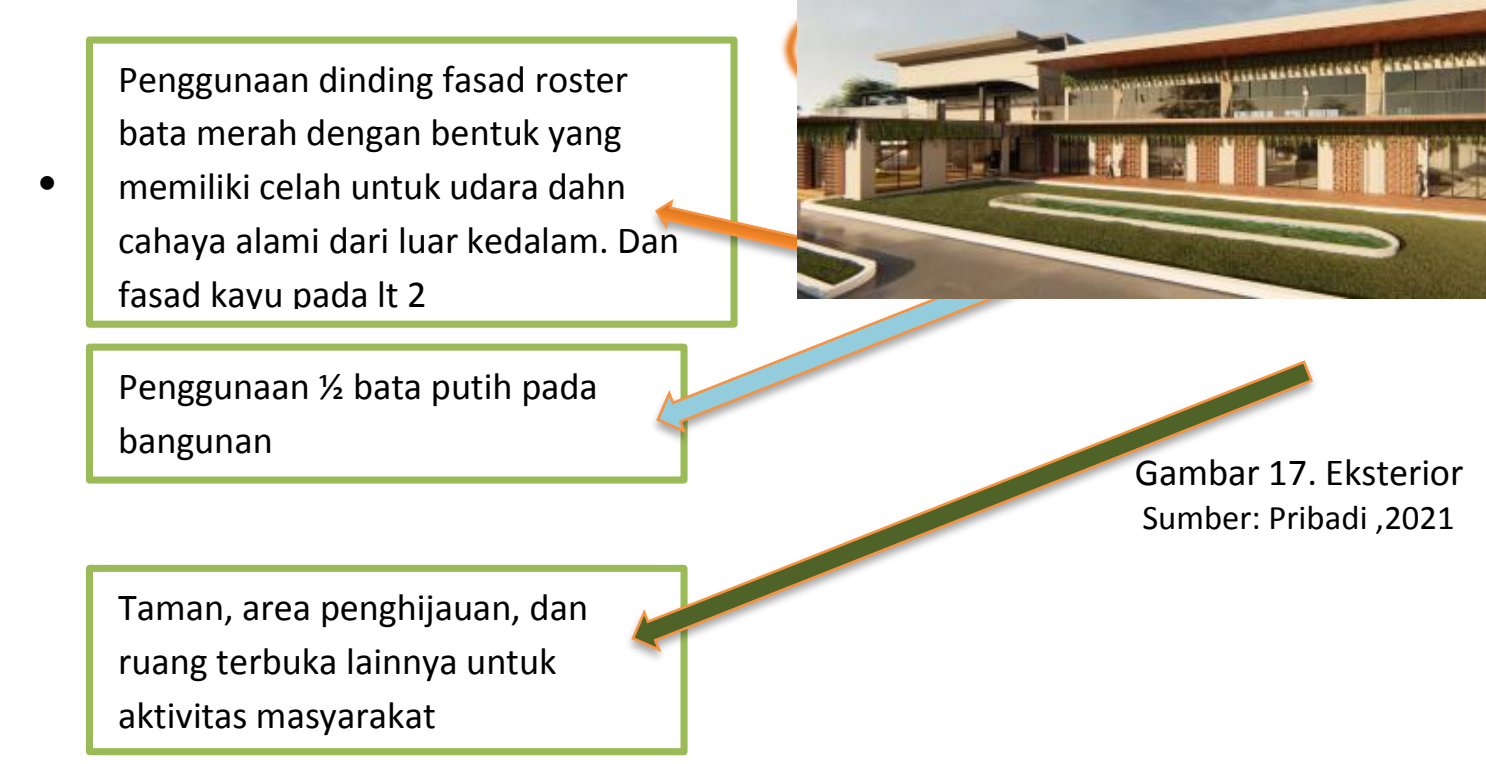

\section{Hasil Desain Rancangan Interior}

Pada interior bangunan ini, adanya bukaan pada tiap sisi bangunan yang dirancang. Agar sirkulasi Interior untuk pengunjung, staff, pegawai dan lainnya mendapatkan cahaya dan udara secara efektif dan alami di dalam ruangan. Penggunaan bukaan pada area daur ulang (lantai 2) yaitu berupa jendela mati dan hidup dari dalam area pengelola dan daur ulang (lantai 1). Agar menciptakan rasa luas pada bangunan. Kemudian, untuk ruang seminar dan staff dirancang juga dengan bukaan. 
Untuk area rekreasi cukup terbuka tanpa adanya jendela, dan penggunaan dinding sebagian dari botol plastic
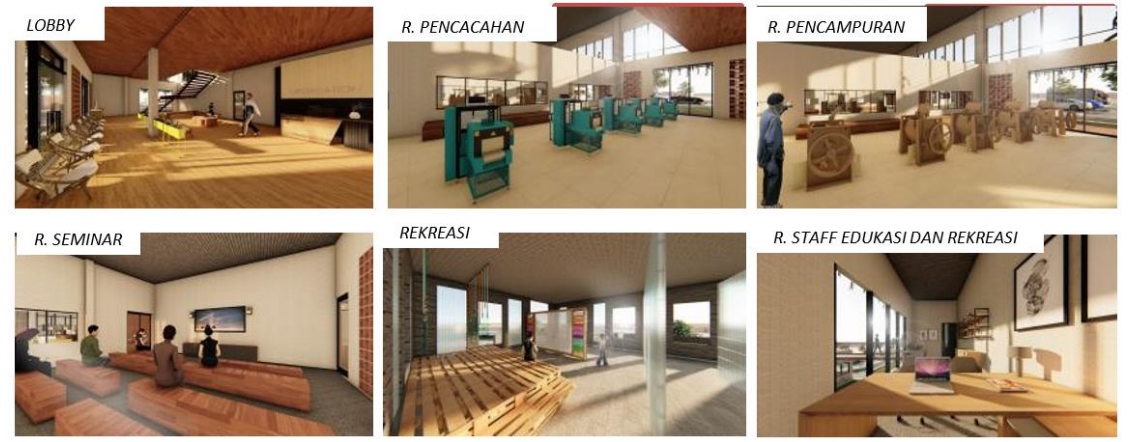

Gambar 18.Interior

Sumber: Pribadi ,2021

\section{HASIL PRODUKSI DAUR ULANG}

Dari sampah yang telah melewati proses pencacahan, pencampuran dan pencetakan maupun tidak akan menghasilkan bahan material bangunan berupa : eco bricks, plastic cladding, paving block dan bata plastik.

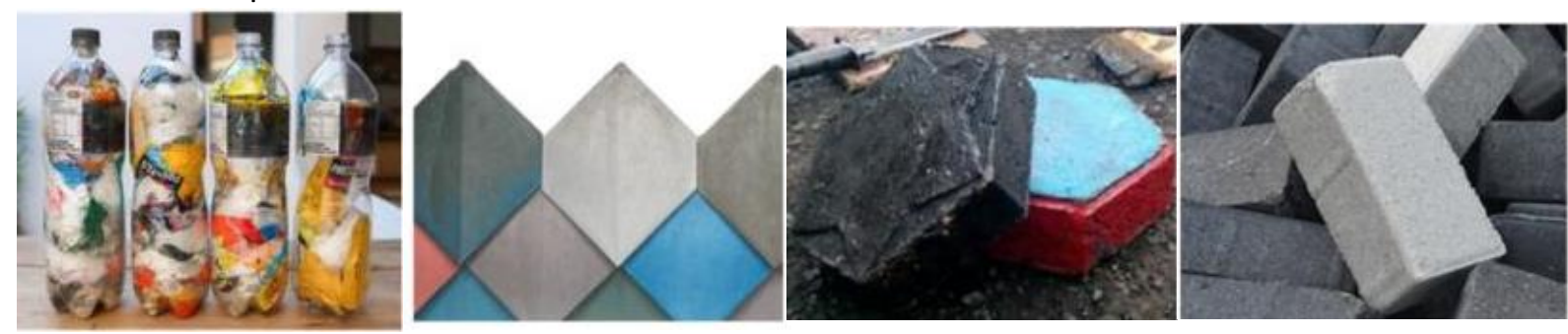

Gambar 19. Eco Bricks, Plastic Cladding, Pavling Block dan Bata Plastik

Sumber: Google ,2021

\section{KESIMPULAN DAN SARAN}

\section{Kesimpulan}

Proyek yang dilatarbelakangi oleh permasalahan sampah ini perlu adanya pemanfaatan yang baik dan bermanfaat, agar bisa digunakan kembali. Maka, dirancanglah ruang daur ulang untuk mewadahi serta menunjang aktivitas proses mengolah sampah sehingga menjadi bahan material bangunan dan atau lainnya yang akan dijual dan diaplikasikan pada Rekreasi. Kemudian ada juga program aktivitas lainnya yaitu : rekreasi (dirancang untuk masyarakat agar bisa merasakan pengalaman baru), edukasi dan RTH untuk masyarakat berupa taman dan lainnya. Proyek ini dirancang dengan pendekatan 5 Prinsip Arsitektur Ekologis (pemanfaatan potensi iklim, penyediaan RTH, material lokal (penerapan3/4R), pengelolaan air. Tanah, dan udara berkelanjutan dan ruang masyarakat). Dengan program yang ditawarkan dalam proyek ini diharapkan dapat mengurangi sampah yang ada di sekitar agar bisa meningkatkan pengetahuan dan perekonomian masyarakat Dadap.

\section{Saran}

Diperlukannya pengamatan lapangan secara langsung untuk melihat kondisi lingkungan sekitar dan studi lanjutan berupa wawancara pada penduduk sekitar Dadap agar mendapatkan lebih banyak data. Sehingga proyek Ruang Daur Ulang dan Rekreasi Sampah ini bisa menjadi proyek yang berguna, aman dan meningkatkan kualitas hidup masyarakat yang lebih baik untuk lingkungannya. 


\section{REFRENSI}

Ayodhia M., (2013), Prinsip-Prinsip Ilmu Ekologi Dalam Arsitektur, diunduh 9 November 2013, $<$ https://ayodiamahardika.wordpress.com/2013/11/09/prinsip-prinsip-ilmu-ekologi-dalamarsitektur/

Bella A., (2021), Ekologi adalah, diunduh 12 Juni 2018, <Ekologi: Pengertian, Prinsip, Manfaat, Jenis, dan Contoh (pakdosen.co.id)

Frick, H., (2007). Dasar-Dasar Arsitektur Ekologis. Kanisius, Yogyakarta.

Metallinou, V.A., (2006). Ecological Propriety and Architecture 86, 15- 22

Nuring A, (2016), Desain Arsitektur Yang Berkelanjutan (Sustainable), diunduh 30 November 2016, $<$ Desain Arsitektur Yang Berkelanjutan (Sustainable) - Arginuring Arsitek

Rahmadiah N. (2019). Arsitektur Bioklimatik Dan Kearifan Lokal (Studi Kasus : Desain Pusat Riset dan Teknologi Energi Terbarukan di Bali), (257-262)

Richtia W. F (2020). Daur Ulang Plastik Untuk Bahan Bangunan. Vol.1 ,2020 .

Setiawan S. (2021), Daur Ulang Limbah Organik Beserta Penanganannya, diunduh 2 Mei 2021, https://www.gurupendidikan.co.id/limbah-organik

Sholihah A., (2018), Pengertian Sampah, Manfaat, Jenis dan Dampaknya (Lengkap), diunduh 25 November 2018, <https://www.studinews.co.id/pengertian-sampah-manfaat-jenis-dandampaknya

Sukawi, W. (2008). Ekologi Arsitektur: Menuju Perancangan Arsitektur Hemat Energi dan Berkelanjutan 1

Student Indonesia. (2017), 11+ Pengertian Sampah Menurut Para Ahli Lengkap, diunduh 19 Maret 2017, https://www.indonesiastudents.com/pengertian-sampah-menurut-para-ahli/

Webmaster, (2020), 2 Teknologi Daur Ulang Sampah Skala Kecil dan Besar, diunduh 19 November2020, < https://dlh.semarangkota.go.id/2-teknologi-daur-ulang-sampah-skalakecil-dan-besar/

Williams B., (2021). Ernst Haeckel and the Origins of Ecology diunduh 5 April 2021, https://www.briangwilliams.us/environmental-history/ernst-haeckel-and-the-origins-ofecology.html

Yeang, K., (1999). The Green Skyscraper: The Basis for Designing Sustainable Intensive Buildings. Prestel, United Kingdom

Yuliani S, (2017). Pendekatan Arsitektur Ekologis Pada Pusat Pengelolaan Sampah Di Surakarta. Arsitektura, Vol. 15, No.2, 483-490. 